\title{
Stem Cell Repair for Cardiac Muscle Regeneration: A Review of the Literature
}

\author{
Georgiana Farrugia,' Rena Balzan.'
}

\begin{abstract}
The notion that the human adult heart is a quiescent organ incapable of self-regeneration has been successfully challenged. It is now evident that the heart possesses a significant ability for repair and regeneration. Stem cells of endogenous cardiac origin are currently considered to possess the greatest ability to differentiate into cardiomyocytes. The major types of cardiac stem cells that show a promising potential to replace damaged cardiomyocytes include C-KIT positive (C-KIT+) cardiac progenitor cells, cardiosphere-derived progenitor cells, islet-1 (Is $1+$ ) cardiac progenitor cells, side-population cardiac progenitor cells, epicardium-derived progenitor cells and stem cell antigen-1 $\left(\mathrm{SCA}_{1+}\right)$ cardiac progenitor cells. Moreover, stem cells of extra-cardiac origin are also thought to restore contractility and vascularization of the myocardium. These include skeletal myoblasts, bone marrow mononuclear cells, mesenchymal stem cells, endothelial progenitor cells as well as embryonic stem cells. The need for further investigation on cardiac stem cell therapeutic strategies still remains.
\end{abstract}

Keywords: Stem Cells; Therapeutics; Regeneration; Myocardium; Infarction (Source: MeSH, NLM).

About the author: Ceorgiana Farrugia is a diagnostic radiographer and a third year medical student at the Faculty of Medicine and Surgery, University of Malta. She is a former Editorin-Chief of EMSA EUROMEDS.

\section{Introduction}

Cardiovascular disease is a leading cause of death worldwide. Following an ischaemic event, the myocardium suffers permanent loss of cardiac tissue and gradually deteriorates towards heart failure. Over 26 million individuals suffer from congestive heart failure worldwide, whilst in Europe alone, approximately 3.5 million patients are newly diagnosed with this condition on a yearly basis.' The major causative factor behind this cardiac pathology lies in the insufficiency of pumping action by the cardiomyocytes, or their loss, following the survival of a myocardial infarction (MI). Following MI, local cardiac compensatory mechanisms are activated, which may in turn, give rise to a decline in cardiac function, or sudden cardiac death. ${ }^{2}$

To date, cardiac transplantation is the first-line treatment for end-stage heart failure. However, this type of treatment is limited primarily by the availability of donor hearts, as well as by the specific immune response triggered by the introduction of foreign tissue. This leaves the recipient with no other choice but to be prescribed with life-long immunosuppressive drugs. Moreover, the prognosis for end-stage heart failure is not so favourable. In fact, only $50 \%$ of newly-diagnosed cases survive the following year, despite receiving adequate pharmacological therapy or an implantation of a mechanical left ventricular assisting device. ${ }^{3}$

Regeneration/repair of damaged or ischaemic cardiomyocytes may be addressed through the use of fully functional and self-renewing stem cells that have the ability to form different cell types, and hence, the potential to restore the viability or function of defective tissue. As can be seen in Figure 1, stem-cell therapy for cardiac dysfunction may be applied either through the implantation of stem cells, or their derivatives, directly into the heart or else via the activation of endogenous cardiac repair mechanisms that have the ability to replace damaged cardiomyocytes and promote vascular reconstruction..$^{4-5}$ For this reason, the main objective behind this literature review

Figure 1. Outline of Stem Cell Therapy for Cardiac Dysfunction

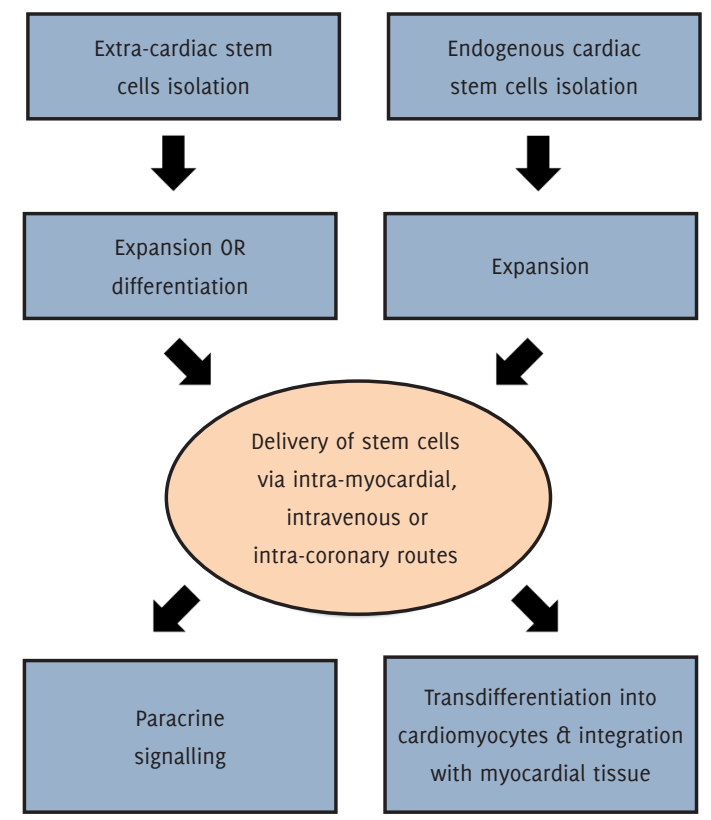

A schematic representation of the potential sequence of events involved in successful regenerative stem cell treatment of cardiac muscle in an infarcted heart. 
lies in highlighting the major types of exogenous and endogenous cardiac stem cell lineages that are thought to enhance the ability of the myocardium to regenerate or be repaired following significant injury or dysfunction.

\section{Search Strategy and Selection Criteria}

A literature search for this review was conducted at the Faculty of Medicine a Surgery Library at the University of Malta in February 2015. Most of the literature was obtained online from various electronic databases such as PubMed Health ${ }^{\circledR}$, Sage ${ }^{\circledR}$ and Science Direct ${ }^{\oplus}$. The initial literature search involved general keywords such as: 'stem cell therapy', 'myocardium', 'regeneration', 'myocardial infarction', 'heart failure' and 'management'. Shortly after, another literature search was conducted using specific keywords such as: 'cardiac stem cells' and 'exogenous stem cells'. Several relevant free access articles were sought after and filtered according to relevance, date and language of publication. The bibliographies of such publications were also searched for potential referencing sources. Whenever possible, primary sources of literature were acquired. The final review consisted of 57 different referencing sources, which were published in English within the past 24 years, from October 1990 to August 2014.

\section{Stem Cells of Endogenous Cardiac Origin}

The heart has traditionally been considered as a post-mitotic organ, with no ability to proliferate or self-renew, since mature cardiomyocytes withdraw from the cell cycle. Contradictory data to this belief started to accumulate when cardiomyocyte proliferation was detected under certain pathological conditions, namely ischaemia and hypertension. ${ }^{6-9}$ In fact, recent data suggests that there are niches within the heart, located within the deep tissue of the atria and apex, which contain stem cells that are able to divide, and are more likely to differentiate into cardiac cells. ${ }^{10-11}$ The major types of cardiac stem cells (CSC) that show a promising potential to replace damaged cardiomyocytes are C-KIT positive (C-KIT+) cardiac progenitor cells, cardiosphere-derived progenitor cells, islet-1 (Isl1+) cardiac progenitor cells, side-population cardiac progenitor cells, epicardium-derived progenitor cells and stem cell antigen-1 $(\mathrm{SCA} 1+)$ cardiac progenitor cells.

\section{C-KIT+ Cardiac Progenitor Cells}

Several scientists sought to explore the existence of circulating stem cells that are specifically housed in the heart and whether these are able to differentiate into cardiac lineages. Most of the initial studies that were conducted worldwide focused on cells expressing the tyrosine-kinase receptor C-KIT+, a known marker of haematopoetic progenitor cells (HPC).

Following MI, C-KIT+ cardiac progenitor cells were found to regenerate cardiomyocytes when injected into an infarcted tissue zone. ${ }^{12}$ This conclusion was based upon the histological staining results, whereby $68 \%$ of cardiac muscle cells within the infarcted tissue were proven to be of exogenous origin and later supported by further studies. ${ }^{10,13-15}$ In addition, throughout the past 5 years, this specific type of CSC has accumulated enough justification for their application in human clinical trials. Favourable effects on cardiac repair and myocardial functional recovery was reported..$^{16-17}$
In these clinical trials, autologous C-KIT+ cardiac progenitor cells were isolated and expanded ex-vivo from post-MI patients undergoing coronary artery bypass grafting (CABC). Subjects were randomized to receive either intracoronary infusion of C-KIT+ cardiac progenitor cells, or conventional therapy. Preliminary findings have demonstrated a significant improvement in left ventricular (LV) function as well as a reduction in infarct size in the group who have received treatment with C-KIT+ cardiac progenitor cells, when compared to the subjects who received conventional therapeutic measures. ${ }^{16-17}$ Despite the integrity of the data generated throughout these clinical trials, concerns have been raised regarding the processes of patient randomization. ${ }^{18}$ Thus, research pertaining to the full spectrum of benefits and downsides of this type of CSC is currently ongoing.

\section{Cardiosphere-derived Progenitor Cells}

The term "cardiosphere" refers to a population of undifferentiated cells that can be isolated via a cardiac biopsy and obtained through enzymatic digestion of explanted cardiac tissue. ${ }^{19}$ Cardiosphere-derived stem cells (CDC) are characterized as a heteregenous cell population, containing a central core of C-KIT+ cardiac progenitor cells that have been previously discussed.

There are various studies that have established the application of $\mathrm{CDC}$ as a promising candidate for cardiac stem cell therapy. The functional benefits of $C D C$ are their superior potency and myocardial repair efficacy compared to other CSC populations. ${ }^{20}$ In fact, in addition to C-KIT+ cardiac progenitor cells, CDC present an alternative source of accumulating data from human clinical trials.

The study involving the cardiosphere-derived autologous stem cells to reverse ventricular dysfunction (CADUCEUS) consisted of a randomised phase 1 clinical trial, that assessed the safety of autologous intracoronary (IC) CDC delivery in post-MI patients. ${ }^{21}$ The $C D C$ were obtained via percutaneous endomyocardial biopsies, expanded ex vivo, and delivered by IC injection into the infarcted coronary arteries 2 to 4 weeks following MI. Magnetic resonance imaging (MRI) at 3 months post IC CDC injection denoted a reduction in scar tissue, increased viability of heart mass, as well as an increased regional systolic wall thickening, when compared to the control group. A statistically significant improvement in overall LV function was not observed. Nevertheless, the preliminary results from this clinical trial demonstrated that $\mathrm{CDC}$ therapy appears to be safe. Indeed, this type of CSC warrants further investigation.

\section{Islet-1 (Is/1+) Cardiac Progenitor Cells}

It is known that progenitor cells in the developing heart are reliant on cardiac-specific transcription factors for their differentiation. Is $1+$ is a transcription factor that is expressed in early cardiac progenitor cells, until they differentiate. Cardiac $|s| 1+$ expression in adults is mainly confined to the sinoatrial node. ${ }^{22}$ Genetic studies have demonstrated that $|s| 1+$ is important for survival, proliferation and migration of early cardiac progenitors. ${ }^{23-25}$ In addition, Isl $1+$ cardiac progenitor cells have been suggested to contribute to various cardiac lineages during in vitro differentiation studies. In fact, it is thought that certain cardiac progenitor cells may be multi-potent, however this 
claim still needs to be demonstrated in vivo..$^{24-27}$

It has recently been depicted that a population of Isl $1+$ expressing cells in the human fetal heart may give rise to cardiac muscle in the post-natal heart. ${ }^{25}$ Previous studies have shown that these types of stem cells can be maintained in their undifferentiated state during in vitro culture, and were later able to differentiate into cardiac muscle as well as smooth muscle. ${ }^{24,26}$ Unfortunately, the relative scarcity of $|s|_{1}+$ cardiac progenitor cells in the human adult heart, their largely non-proliferative state in the post-natal period and their lack of considerable expansion post MI, cast doubt on their application for repair and regeneration of the myocardium. ${ }^{25}$

\section{Side-population Cardiac Progenitor Cells}

Side-population cardiac progenitor cells (SP) possess a unique ability to efflux a DNA binding dye, namely Hoechst 33342, that is conferred by an ATP-binding transporter. In humans, these types of transporters are encoded by the $A B C C_{2}$ gene, which can be used as a determinant of the cardiac SP cells during flow cytometry. ${ }^{5}$

There are few studies demonstrating the application of this type of CSC in attempting to regenerate the myocardium after an ischaemic event. However, it has been suggested that the infusion of cardiac SP cells into cryo-injured hearts led to the homing of these cells into the infarcted tissue, and resulted in differentiation of a proportion of surviving cells into cardiac muscle or smooth muscle. ${ }^{28}$ The combination of cell surface marker studies with lineage tracing experiments in the near future will provide a more accurate tracking of the SP fate in vivo, and as a result, better characterization of their cardiac regenerative properties.

\section{Stem Cell Antigen-1 (SCA1+) Cardiac Progenitor Cells}

Although the $S C_{1}$ gene is not present in humans, there are related genes of the LYG family that are involved in cell adhesion, migration and extracellular matrix (ECM) degradation. $\mathrm{SCA}_{1}+$ cardiac progenitor cells were first investigated in the adult murine myocardium, and were later classified as a type of CSC which lack haemopoeitic lineage markers. ${ }^{29}$

It is suggested that in combination with oxytocin, the differen- tiation of $\mathrm{SCA}_{1}+$ cardiac progenitor cells in vitro, may result in the formation of spontaneously beating cardiomyocytes. ${ }^{30}$ This statement has been supported by further experimentation. ${ }^{31}$ Moreover, it has been shown that cardiomyocytes require stem cell antigen-1 to upregulate the secretion of paracrine effectors which induce angiogenesis and limit cardiac apoptosis. Therapeutically, it is thought that stem-cell antigen-1 may promote CSC survival following engraftment into injured cardiac tissue, which will in turn influence revascularization and myocardial repair. ${ }^{5}$ However, their potential to form cardiac muscle in the elderly population is currently being questioned.

Table 1 summarizes the reviewed information about the major types of CSC that have gathered significant evidence in favour of repair or regeneration of the myocardium following cardiac dysfunction.

\section{Stem Cells of Extra-cardiac Origin}

Exogenous stem cells (ESC) comprise at least two different groups of cells: the bone marrow derived cells and a circulating pool of stem cells, which are partly derived from the bone marrow. The most extensively studied extra-cardiac stem cells to date are the bone marrow derived cells. In fact, this type of ESC has proceeded to clinical trials in relation to acute and chronic myocardial infarction, as well as dilated cardiomyopathy. The major types of stem cells of extra-cardiac origin that show promising potential to be applied in cardiac stem cell therapy include skeletal myoblasts, bone marrow mononuclear cells, mesenchymal stem cells, endothelial progenitor cells as well as embryonic stem cells.

\section{Skeletal Myoblasts}

Skeletal myoblasts (SKM) can be referred to as progenitor cells that are located within the basal lamina of skeletal muscle (SM) fibres. Their activation is often a result of injury, which is manifested by the mobilization, proliferation, differentiation and ultimately the fusion into new muscle fibres. ${ }^{32}$ This type of ESC may be isolated via a SM biopsy and expanded in vitro. SKM were amongst the first types of ESC that were utilized in clinical trials, particularly in the setting of chronic MI. ${ }^{33} \mathrm{An}$ advantage of SKM over other types of ESC is that they are resistant to ischaemia. This factor increases their chance of survival following the development of an infarcted scar. ${ }^{34-36}$

Table 1. Summary of Endogenous Stem Cell Populations

\begin{tabular}{|c|c|c|c|c|c|}
\hline Stem Cell Type & Suggested Origin & In Vitro Potency & In Vivo Fate & Clinical Trials & References \\
\hline Islet-1 cardiac progenitors & $\begin{array}{l}\text { Embryonic second heart } \\
\text { field }\end{array}$ & Suggested to be multipotent & Not applicable & None & Ref $22,24-27$ \\
\hline $\begin{array}{l}\text { Stem cell antigen-1 cardiac } \\
\text { progenitors }\end{array}$ & Poorly defined & $\begin{array}{l}\text { Cardiac muscle, chondrocytes } \\
\text { it osteocytes }\end{array}$ & Cardiac muscle & None & \\
\hline
\end{tabular}

The major types of cardiac stem cells that have gathered significant evidence in favour of repair or regeneration of the myocardium following cardiac dysfunction are shown. In comparison with extra-cardiac stem cells, endogenous cardiac stem cells have shown a more promising potential for cardiovascular differentiation and a reduced risk of tumour formation. However, these types of cells are thought to undergo senescence and their availability may be less prominent in adult tissues. 
The transplantation of SKM has been evaluated clinically in attempt to restore cardiac function, particularly as a therapeutic intervention for heart failure. Studies with a 4-month and 10-month follow-up both demonstrated an increase in left ventricular ejection fraction (LVEF) and an overall improvement in systolic shortening in SKM-implanted tissue. ${ }^{35,37}$ Moreover, strengthening of the left ventricular wall and a reduction in size of the post-infarction scars were observed in enrolled subjects.

Reported adverse effects related to the SKM transplantation procedure, include ventricular tachycardia (VT) and atrial fibrillation (AF). Although these arrhythmias were detected in a short time frame following the intervention, most were well-tolerated and resolved clinically. ${ }^{35}$ The future of such promising strategy solely lies in its modification through genetic engineering, with the aim of potentiating the action of SKM paracrine effectors and perfecting their cardiotrophic action.

\section{Bone Marrow Mononuclear Cells}

The bone marrow mononuclear subset is heterogenous and comprises HPC, mesenchymal stem cells (MSC), as well as endothelial progenitor cells (EPC). ${ }^{38}$ These types of adult ESC have long been considered as an attractive option to be studied in light of their application in the promotion of growth of myocardial tissue. Despite the fact that their differentiation potential is less compared to embryonic stem cells and HPC comprise less than $0.1 \%$ of bone marrow mononuclear cell (BMMNC) samples, a wave of clinical trials using the latter still took place in the past decade.

Approximately 2000 subjects have received BMMNC therapy for ischaemic cardiomyopathy, collectively amongst three different studies. ${ }^{39-41}$ Unfortunately, cardiac function improvements in these clinical trials were modest. Similarly, in another phase-2 clinical trial, no significant improvement in LV end-systolic volume was reported. ${ }^{42}$ Nonetheless, some scientists believe that cardiac cell therapy with BMMNC may prosper in combination with growth factors or other proteins that are capable of angiogenesis or cardiomyocyte proliferation. ${ }^{4}$ Thus, attempts to achieve favourable cardiac repair post-MI using this type of ESC are still underway.

\section{Mesenchymal Stem Cells}

MSC represent another group of stem cells that are located in the bone-marrow, as well as in other tissues such as umbilical cord blood and adipose tissue. This type of ESC has been said to differentiate into cardiomyocytes in the presence of the demethylating agent 5 -azacytidine or when co-cultured with other cardiomyocytes. ${ }^{43-45}$ Contrastingly, in vitro differentiation into functional cardiomyocytes failed. ${ }^{45}$

The very first clinical trial depicting post-Ml treatment with MSC infusions took place six years ago. It was reported that a significant improvement in LV function occurred three months post-injection in enrolled patients. ${ }^{34}$ Similarly, a more recent study demonstrated that MSC possess the ability to reduce infarct size and increase contractile improvement. ${ }^{47}$ on top of these benefits, a limited-sample study also reported an increased perfusion in the infarcted tissue. ${ }^{47}$

In spite of the fact that favourable findings have been obtai- ned during multiple clinical trials, some researchers have noted that MSC engraft poorly in cardiac tissue. Thus, theories have now shifted to support a mechanism involving paracrine mediators that are able to promote angiogenesis, as well as adipose-tissue derived stem cells that are thought to promote new cardiomyocyte formation. .6-49 $^{-1}$

\section{Endothelial Progenitor Cells}

Angiogenesis was initially thought to occur solely through the proliferation of mature endothelial cells. However, this belief was recently challenged upon the discovery that bone-marrow derived stem cells are able to incorporate into the microvasculature of prominent injury sites, particularly following MI, cancer or burns..$^{50}$ Similar to skeletal myoblasts, EPC are resistant to ischaemia and thus, are considered to be an intriguing concept for cardiac therapeutic intervention.

The initial pre-clinical studies with implanted EPC into infarcted myocardium have resulted in improved LV function and inhibited fibrosis. ${ }^{51-52}$ Small clinical trials have later confirmed the improvement of LV function in human cases of both acute and chronic myocardial ischaemia. ${ }^{33}$ Nonetheless, the major concern regarding the application of EPC for cardiac muscle regeneration lies in the fact that the circulating pool of EPC is reduced in patients with cardiac diseases, and co-morbidities such as diabetes mellitus, hypertension or hypercholesterolaemia. ${ }^{54-55}$ This issue is very problematic since this type of therapy was designed to treat patients with coronary artery disease and cardiovascular risk factors. Thereby, more research aimed at enhancing the therapeutic benefits in patients with cardiovascular disease is required.

\section{Embryonic Stem Cells}

Embryonic stem cells can be harvested from the inner cell mass of a blastocyst. Under ideal settings, they are able to give rise to multiple lines of cells to produce a particular organ or tissue; including the growth of new cardiomyocytes. However, considerable technical and ethical issues exist with the application of this type of ESC in human subjects.

Primarily, the inadvertent transplantation of undifferentiated pluripotent stem cells has been shown to pose significant risks to the host due to their large tumorigenic potential, when compared to other stem cell lineages. ${ }^{5}$ Moreover, this type of ESC is more likely to induce host immune rejection following transplantation due to its allogeneity. Thereby, it is necessary for these limitations to be fully addressed before the successful application of embryonic stem cells in cardiac muscle regeneration. Table 2 summarizes the reviewed information about the major types of ESC that have gathered significant evidence in favour of repair or regeneration of the myocardium following cardiac dysfunction.

\section{Delivery of Transplanted Stem Cells into the Myocardium}

A consensus still needs to be found with regards to the optimal method of delivery of transplanted stem cells into the myocardium. The most promising methods include IC, intramyocardial (IM), or intravenous (IV) routes. The most clinically practiced form of stem cell delivery is, by far, the IC approach. This procedure is usually carried out simultaneously during a percutaneous coronary intervention following an MI, where a direct 
Table 2. Summary of Exogenous Stem Cell Populations

\begin{tabular}{|c|c|c|c|c|c|}
\hline Stem Cell Type & Suggested Origin & $\begin{array}{l}\text { Clinical } \\
\text { Trials }\end{array}$ & Advantages & Disadvantages & References \\
\hline Skeletal myoblasts & Mature muscle & $\begin{array}{l}\text { Phase } 1 \text { ct } \\
\text { Phase } 2\end{array}$ & $\begin{array}{l}\text { Wide range of scalability, } \\
\text { resistant to ischaemia, mul- } \\
\text { tipotency and no teratoma } \\
\text { formation }\end{array}$ & $\begin{array}{l}\text { Have been associated with cardiac arr- } \\
\text { hythmias and dysynchronous beating }\end{array}$ & $\begin{array}{l}\text { Ref } 32-33 \\
35-37\end{array}$ \\
\hline $\begin{array}{l}\text { Bone marrow } \\
\text { mononuclear cells }\end{array}$ & Bone marrow & $\begin{array}{l}\text { Phase } 1 \text { it } \\
\text { Phase } 2\end{array}$ & $\begin{array}{l}\text { Easy to isolate for implan- } \\
\text { tation }\end{array}$ & $\begin{array}{l}\text { Necessitates more in vivo investigation } \\
\text { on their nature of cardiovascular diffe- } \\
\text { rentiation }\end{array}$ & Ref $39-42$ \\
\hline Mesenchymal cells & $\begin{array}{l}\text { Bone marrow } \mathrm{t} \\
\text { adipose tissue }\end{array}$ & $\begin{array}{l}\text { Phase } 1 \text { at } \\
\text { Phase } 2\end{array}$ & $\begin{array}{l}\text { Easy to expand in culture, } \\
\text { multipotency and less immu- } \\
\text { nogenic than other types of } \\
\text { stem cells }\end{array}$ & Wide range of heterogeneity & $\begin{array}{l}\text { Ref } 34,46 \\
47-49\end{array}$ \\
\hline $\begin{array}{l}\text { Endothelial progenitor } \\
\text { cells }\end{array}$ & $\begin{array}{l}\text { Bone marrow ¿t } \\
\text { peripheral blood }\end{array}$ & $\begin{array}{l}\text { Phase } 1 \text { ct } \\
\text { Phase } 2\end{array}$ & $\begin{array}{l}\text { Possess a promising potential } \\
\text { for neovasculogenesis }\end{array}$ & $\begin{array}{l}\text { Small amounts present in adults with } \\
\text { cardiovascular disease and related } \\
\text { comorbidities }\end{array}$ & Ref $50-55$ \\
\hline
\end{tabular}

The major types of extra-cardiac stem cells that have gathered significant evidence in favour of repair or regeneration of the myocardium following cardiac dysfunction are shown.

administration of stem cells is delivered into the myocardium via the coronary arteries. Whilst it is considered as safe and efficient, this method fails to deliver stem cells to myocardial sites of interest that are poorly perfused..$^{56}$

The possibility of using IV injections to deliver stem cells into the myocardium is thought to be highly inefficient, albeit inexpensive and a minimally invasive option. Thus, it is currently being investigated for use only in patients following MI, but not in those with chronic heart failure. On the other hand, the IM method provides the most precise delivery out of all three options discussed above. However, its major limitation lies in that it is classified as highly invasive, therefore critically ill patients would be less likely to tolerate this route of administration.

\section{Conclusion}

The notion that the human adult heart is a quiescent organ incapable of self-regeneration has been successfully challenged over the past decade. It is now evident that the heart possesses a significant ability for repair and regeneration. Several types of stem cells have shown promising potential in cardiac muscle regeneration, being it through the delivery of extra-cardiac lineages or the activation of endogenous mechanisms. To date, the major stem cell lineages that have lead to fruitful findings in animal studies or human clinical trials are the C-KIT+ cardiac progenitor cells and the skeletal myoblasts, although their limitations cannot be overlooked. Additional investigations are required in order to elucidate the ideal types of stem cells as well as the optimal method for delivery into the myocardium. Indeed, the greatest barrier to the application of successful stem cell therapy in the future management of common cardiovascular diseases, lies within perfecting the recruitment, survival and long term engraftment of stem cell lineages that possesses promising functional myocardium characteristics. Moreover, further research is needed to fully comprehend the process of endogenous paracrine signaling as well as the complex molecular interactions that occur between the donor stem cells and the host myocardial tissue. 


\section{References}

1. López-Sendón J. The heart failure epidemic. Medicographia. 2011 Apr;33(4):363-9.

2. Orn S, Manhenke C, Anand IS, Squire I, Nagel E, Edvardsen T, et al. Effect of left ventricular scar size, location and transmurality on left ventricular remodeling with healed myocardial infarction. Am J Cardiol. 2007 Apr 15;99(8):110914.

3. Nir SG, David R, Zaruba M, Franz WM, Itskovitz-Eldor J. Human embryonic stem cells for cardiovascular repair. Cardiovasc Res. 2003 May 1;58(2):313-23. 4. Laflamme MA, Murry CE. Heart regeneration. Nature. 2011 May 19;473(7347): 326-35.

5. Matar AA, Chong JJ. Stem cell therapy for cardiac dysfunction. Springerplus. 2014 Aug;3:440.

6. Anversa P, Palackal T, Sonnenblick EH, Olivetti G, Capasso JM. Hypertensive cardiomyopathy. Myocyte nuclei hyperplasia in the mammalian heart. J Clin Invest. $1990 \mathrm{Apr} ; 85$ (4):994-7.

7. Kajstura J, Leri A, Finato N, Di Loreto C, Beltrami CA, Anversa P. Myocyte proliferation in end-stage cardiac failure in humans. Proc Natl Acad Sci U S A. 1998 Jul 21;95(15):8801-5.

8. Beltrami AP, Urbanek K, Kajstura J, Yan SM, Finato N, Bussani R, et al. Evidence that human cardiac myocytes divide after myocardial infarction. New Eng J Med. 2001 Jun 7;344(23):1750-7.

9. Joggerst SJ, Hatzopoulos AK. Stem cell therapy for cardiac repair: benefits and barriers. Expert Rev Mol Med. 2009 Jul 8;11:e20.

10. Urbanek K, Cesselli D, Rota M, Nascimbene A, De Angelis A, Hosoda T, et al. Stem cell niches in the adult mouse heart. Proc Natl Acad Sci U S A. 2006 Jun 13;103(24):9226-31.

11. Collins JM, Russell B. Stem cell therapy for cardiac repair. J Cardiovasc Nurs. 2009 Mar-Apr;24(2):93-7.

12. Orlic D, Kajstura J, Chimenti S, Limana F, Jakoniuk I, Quaini F, et al. Mobilized bone marrow cells repair the infarcted heart, improving function and survival. Proc Natl Acad Sci U S A. 2001 Aug 28;98(18):10344-9.

13. Beltrami AP, Barlucchi L, Torella D, Baker M, Limana F, Chimenti S, et al. Adult cardiac stem cells are multipotent and support myocardial regeneration. Cell. 2003 Sep 19;114(6):763-76.

14. Bearzi C, Rota M, Hosoda T, Tillmanns J, Nascimbene A, De Angelis A, et al. Human cardiac stem cells. Proc Natl Acad Sci U S A. 2007 Aug 28;104(35):1406873.

15. Boni A, Urbanek K, Nascimbene A, Hosoda T, Zheng H, Delucchi F, et al. Notch1 regulates the fate of cardiac progenitor cells. Proc Natl Acad Sci U S A. 2008 Oct 7;105(40):15529-34.

16. Bolli R, Chugh AR, D'Amario D, Loughran JH, Stoddard MF, Ikram S, et al. Cardiac stem cells in patients with ischaemic cardiomyopathy (SCIPI0): initial results of a randomized phase 1 trial. Lancet. 2011 Nov 26;378(9806):1847-57. 17. Chugh AR, Beache GM, Loughran JH, Mewton N, Elmore JB, Kajstura J, et al. Administration of cardiac stem cells in patients with ischaemic cardiomyopathy: the SCIPIO trial: surgical aspects and interim analysis of myocardial function and viability by magnetic resonance. Circulation. 2012 Sep 11;126(11 Suppl 1):S54-64.

18. Nowbar AN, Mielewczik M, Karavassilis M, Dehbi HM, Shun-Shin MJ, Jones $S$, et al. Discrepancies in autologous bone marrow stem cell trials and enhancement of ejection fraction (DAMASCENE): weighted regression and meta-analysis. BMJ. 2014 Apr 28;348:g2688.

19. Messina E, De Angelis L, Frati G, Morrone S, Chimenti S, Fiordaliso F, et al. Isolation and expansion of adult cardiac stem cells from human and murine heart. Circ Res. 2004 Oct 29;95(9):911-21.

20. Li TS, Cheng K, Malliaras K, Smith RR, Zhang Y, Sun B, et al. Direct comparison of different stem cell types and subpopulations reveals superior paracrine potency and myocardial repair efficacy with cardiosphere-derived cells. J Am Coll Cardiol. 2012 Mar 6;59(10):942-53.

21. Makkar RR, Smith RR, Cheng K, Malliaras K, Thomson LE, Berman D, et al.
Intracoronary cardiosphere-derived cells for heart regeneration after myocardial infarction (CADUCEUS): a prospective, randomised phase-1 trial. Lancet. 2012 Mar 10;379(9819):895-904.

22. Weissman IL, Anderson DJ, Gage F. Stem and progenitor cells: origins, phenotypes, lineage commitments, and transdifferentiations. Annu Rev Cell Dev Biol. 2001;17:387-403.

23. Laugwitz KL, Moretti A, Caron L, Nakano A, Chien KR. Islet1 cardiovascular progenitors: a single source for heart lineages? Development. 2008 Jan;135(2):193-205.

24. Laugwitz KL, Moretti A, Lam J, Gruber P, Chen Y, Woodard S, et al. Postnatal $|s| 1+$ cardioblasts enter fully differentiated cardiomyocyte lineages. Nature. 2005 Feb 10;433(7026):647-53.

25. Chong JJ, Forte E, Harvey RP. Developmental origins and lineage descendants of endogenous adult cardiac progenitor cells. Stem Cell Res. 2014 Nov;13(3 Pt B):592-614.

26. Moretti A, Caron L, Nakano A, Lam JT, Bernshausen A, Chen Y, et al. Multipotent embryonic Isl1+ progenitor cells lead to cardiac, smooth muscle, and endothelial cell diversification. Cell. 2006 Dec 15;127(6):1151-65.

27. Bu L, Jiang X, Martin-Puig S, Caron L, Zhu S, Shao Y, et al. Human Isl1+ heart progenitors generate diverse multipotent cardiovascular cell lineages. Nature. 2009 Jul 2;460(7251):113-7.

28. Oyama T, Nagai T, Wada H, Naito AT, Matsuura K, Iwanaga K, et al. Cardiac side population cells have a potential to migrate and differentiate into cardiomyocytes in vitro and in vivo. J Cell Biol. 2007 Jan 29;176(3):329-41.

29. Oh H, Bradfute SB, Gallardo TD, Nakamura T, Gaussin V, Mishina Y, et al. Cardiac progenitor cells from adult myocardium: homing, differentiation and fusion after infarction. Proc Natl Acad Sci U S A. 2003 Oct 14;100(21):12313-8. 30. Matsuura K, Nagai T, Nishigaki N, Oyama T, Nishi J, Wada H, et al. Adult cardiac Sca-1-positive cells differentiate into beating cardiomyocytes. J Biol Chem. 2004 Mar 19;279(12):11384-91.

31. Wang X, Hu Q, Nakamura Y, Lee J, Zhang G, From AH, et al. The role of the sca-1+/CD31-cardiac progenitor cell population in postinfarction left ventricular remodeling. Stem Cells. 2006 Jul;24(7):1779-88.

32. Ciecierska A, Chodkowska K, Motyl T, Sadkowski T. Myogenic cells applications in regeneration of post-infarction cardiac tissue. J Physio Pharmacol. 2013 Aug;64(4):401-8.

33. Hare JM, Chaparro SV. Cardiac regeneration and stem cell therapy. Curr Opin Organ Transplant. 2008 Oct;13(5):536-42.

34. Hare JM, Traverse JH, Henry TD, Dib N, Strumpf RK, Schulman SP, et al. A randomized, double-blind, placebo-controlled, dose-escalation study of intravenous adult human mesenchymal stem cells (prochymal) after acute myocardial infarction. J Am Coll Cardiol. 2009 Dec 8;54(24):2277-86.

35. Menasché P. Skeletal myoblasts and cardiac repair. J Mol Cell Cardiol. 2008 0ct; $45(4): 545-53$.

36. Perumal Srinivasan S1, Neef K, Treskes P, Liakopoulos 0J, Stamm C, Cowan $D B$, et al. Enhanced gap junction expression in myoblast-containing engineered tissue. Biochem Biophys Res Commun. 2012 Jun 8;422(3):462-8.

37. Zhang F, Yang Z, Chen Y, Qin J, Zhu T, Xu D, et al. Clinical cellular cardiomyoplasty: technical considerations. J Card Surg. 2003 May-Jun;18(3):268-73. 38. Arnous S, Mozid A, Martin J, Mathur A. Bone marrow mononuclear cells and acute myocardial infarction. Stem Cell Res Ther. 2012 Jan 17;3(1):2.

39. Abdel-Latif A, Bolli R, Tleyjeh IM, Montori VM, Perin EC, Hornung CA, et al. Adult bone marrow-derived cells for cardiac repair: a systematic review and meta-analysis. Arch Intern Med. 2007 May 28;167(10):989-97.

40. Martin-Rendon E, Brunskill SJ, Hyde CJ, Stanworth SJ, Mathur A, Watt SM. Autologous bone marrow stem cells to treat acute myocardial infarction: a systematic review. Eur Heart J. 2008 Aug;29(15):1807-18.

41. Clifford DM, Fisher SA, Brunskill SJ, Doree C, Mathur A, Clarke MJ, et al. Long-term effects of autologous bone marrow stem cell treatment in acute myocardial infarction factors that may influence outcomes. Plos One. 2012 May; $7(5): e 37373$. 
42. Perin EC, Willerson JT, Pepine CJ, Henry TD, Ellis SC, Zhao DX, et al. Effect of transendocardial delivery of autologous bone marrow mononuclear cells on functional capacity, left ventricular function, and perfusion in chronic heart failure: the FOCUS-CCTRN trial. JAMA. 2012 Apr 25;307(16):1717-26.

43. Wakitani S, Saito T, Caplan Al. Myogenic cells derived from rat bone marrow mesenchymal stem cells exposed to 5-azacytidine. Muscle Nerve. 1995 Dec;18(12):1417-26.

44. Rangappa S, Entwistle JW, Wechsler AS, Kresh JY. Cardiomyocyte-mediated contact programs human mesenchymal cells to express cardiogenic phenotype. J Thorac Cardiovasc Surg. 2003 Jul; 126(1):124-32.

45. Rose RA, Jiang H, Wang X, Helke S, Tsoporis JN, Gong N, et al. Bone marrow-derived mesenchymal stromal cells express cardiac-specific markers, retain the stromal phenotype, and do not become functional cardiomyocytes in-vitro. Stem Cells. 2008 Nov;26(11):2884-92.

46. Heldman AW, DiFede DL, Fishman JE, Zambrano JP, Trachtenberg BH, Karantalis $\mathrm{V}$, et al. Transendocardial mesenchymal stem cells and mononuclear bone marrow cells for ischemic cardiomyopathy: the TAC-HFT randomized trial. JAMA. 2014 Jan 1;311(1):62-73.

47. Karantalis V, Difede DL, Gerstenblith G, Pham S, Symes J, Zambrano JP, et al. Autologous mesenchymal stem cells produce concordant improvements in regional function, tissue perfusion, and fibrotic burden when administered to patient undergoing coronary artery bypass grafting: the Prospective Randomized Study of Mesenchymal Stem Cell Therapy in Patients Undergoing Cardiac Surgery (PROMETHEUS) trial. Circ Res. 2014 Apr 11;114(8):1302-10. 48. Li H, Zuo S, He Z, Yang Y, Pasha Z, Wang Y, et al. Paracrine factors released by CATA- 4 overexpressed mesenchymal stem cells increase angiogenesis and cell survival. Am J Physiol Heart Circ Physiol. 2010 Dec;299(6):H1772-81.

49. Williams AR, Hatzistergos KE, Addicott B, McCall F, Carvalho D, Suncion $V$, et al. Enhanced effect of combining human cardiac stem cells and bone marrow mesenchymal stem cells to reduce infarct size and to restore cardiac function after myocardial infarction. Circulation. 2013 Jan 15;127(2): 213-23. 50. Mund JA, Case J. The role of circulating endothelial progenitor cells in tumour angiogenesis. Curr Stem Cell Res Ther. 2011 Jun;6(2):115-21.

51. Kawamoto A, Tkebuchava T, Yamaguchi J, Nishimura H, Yoon YS, Milliken C, et al. Intramyocardial transplantation of autologous endothelial progenitor cells for therapeutic neovascularization of myocardial ischemia. Circulation. $2003 \operatorname{Jan} 28 ; 107(3): 461-8$.

52. Jujo K, li M, Losordo DW. Endothelial progenitor cells in neovascularization of infarcted myocardium. J Mol Cell Cardiol. 2008 0ct;45(4):530-44.

53. Klein HM, Ghodsizad A, Marktanner R, Poll L, Voelkel T, Mohammad Hasani $M R$, et al. Intramyocardial implantation of $\mathrm{CD}_{133}+$ stem cells improved cardiac function without bypass surgery. Heart Surg Forum. 2007 Jun;10(1):E66-9. 54. Vasa M, Fichtlscherer S, Aicher A, Adler K, Urbich C, Martin H, et al. Number and migratory activity of circulating endothelial progenitor cells inversely correlate with risk factors for coronary artery disease. Circ Res. 2001 Jul 6;89(1):E1-7.

55. Imanishi T, Moriwaki C, Hano T, Nishio I. Endothelial progenitor cell senescence is accelerated in both experimental hypertensive rats and patients with essential hypertension. J Hypertens. 2005 0ct;23(10):1831-7.

56. Sheng CC, Zhou L, Hao J. Current stem cell delivery methods for myocardial repair. Biomed Res Int. 2013;2013:547902.

\section{Acknowledgments}

The authors would like to thank the three respective peer reviewers of this narrative review paper for their suggestions and contribution.

Conflict of Interest Statement at Funding

The author has no funding, financial relationships or conflicts of interest to disclose.

\section{Author Contributions}

Conceptualization, Data collection, Data analysis and interpretation, Writing: FG. Critical revision of the manuscript, Approval of the final version, Administrative/technical advice: RB

Cite as:

Farrugia G, Balzan R. Stem cell repair for cardiac muscle regeneration: a review of the literature. Int J Med Students. 2016 Jan-Apr;4(1):19-25. 